\title{
Postpartum Care Impact on Malayan Mothers in Pontianak, Indonesia
}

\author{
Ummy Yuniantini ${ }^{1}$
}

\section{${ }^{1}$ Akademi Kebidanan Panca bhakti Pontianak, Indonesia}

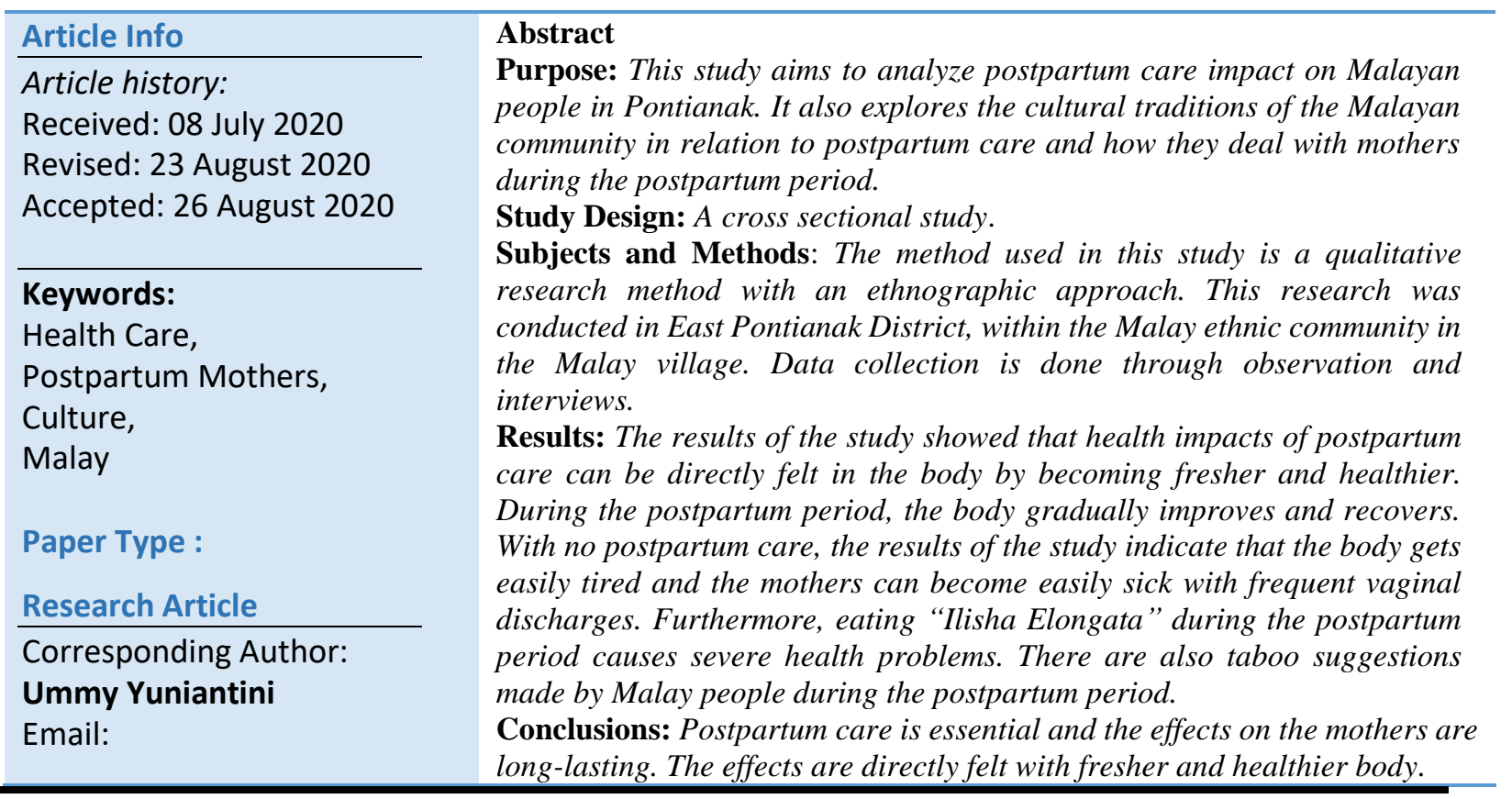

\section{Introduction}

The population in the city of Pontianak is dominated by Malayans and Chinese. The Malayans are considered as the original ethnic group in East Pontianak District, while the Chinese, Madurese, and others are regarded as ethnic migrants. Malayan tribes occupy the first position in the city of Pontianak. The customs and traditions are attached to the majority of the people who are there and carried on for generations and believed to be beneficial to them. Ancestors have bequeathed various kinds of traditional wisdom which is a cultural wealth that grows and develops in the society. This traditional wisdom is empirically important to defend the noble values of the culture. One of the customs that is still practiced by Malayan people in Pontianak is health care for mothers after giving birth or during the postpartum period.

The postpartum period or the 'puerperium' is the period after childbirth, the recovery, healing, and return of uterine to its normal position. The period begins after the birth of the placenta up to six weeks (42 days) after delivery. During the postpartum period, mothers need care and supervision that is done during the stay in the hospital and after discharge from the hospital (Pitriani \& Andriyani 2014; Mitra, et al., 2015). The postpartum is a period that looks safe in many aspects. However, it is sometimes underestimated; resulting in lack of attention to the mother's physical and psychological condition after giving birth. Sometimes 
severe complications might occur and threaten the life of the mother, if no medical treatment is taken. In fact, the postpartum is a crucial period during which certain complications can endanger the mother's condition (Fisher et. al 2009; Misri, 2010). Postpartum hemorrhage, infection, postpartum blues, and even death become a threat from complications experienced by the mother during the postpartum (Nour, 2014). Lack of health control during the postpartum period also contributes to the high maternal mortality rate (MMR) (Triana et al., 2015).

According to a WHO report (2017), every day 810 mothers in the world die from diseases or complications related to pregnancy and childbirth. Data from the Indonesian Ministry of Health in 2015 showed that of 100,000 live births in Indonesia, 305 of them ended in maternal death. In 2016 in the province of West Kalimantan, maternal deaths were recorded at 95 per 100,000 live births. The maternal mortality rate in Pontianak among 13 other districts in West Kalimantan is 3 per 100,000 live births (Ministry of Health, 2007; Health Office of West Kalimantan Province, 2016; Health Office of Pontianak City, 2017). Malayan people believe that during childbirth a mother's health must be very attentive. Complications that occur in the postpartum are very dangerous for the mother and can cause death (Say et al., 2014; Vogel et al., 2014). In Malayan ethnic group, the complications that occur during the postpartum are called 'Bentan'. Bentan is a condition in which the mother experiences various complications for forty five days. These complications vary and they sometimes prevent the mother from resuming any work.

Postpartum maternal health care for Malayans in Pontianak is considered as compulsory care that they have to do after giving birth. Although there are now doctors, midwives and other health workers, the Malayans continue to carry out various taboos and suggestions inherited from their cultural traditions. Though they consult health workers, they continue to follow the tradition of the Malayans in Pontianak in maintaining health during the postpartum. Health workers namely doctors and midwives in Pontianak also understand this condition. They still respect the existing customs and straighten out if there is a distorted belief. Health workers, especially midwives, also collaborate with local shamans, so that the community is assisted by health workers and directed to the delivery of health services.

This research study is an attempt to understand the postpartum care in the Malayan ethnic community residing in the Malayan village. It also aims to measure the possible effects of receiving good postpartum care on mothers and how cultural traditions of the community shape people's perception of this health condition.

\section{Methodology and Procedures}

Based on the types and sources of data in this study, the techniques used in data collection are non-participation observation and non-depth interviews. The technique used for determining the participant is snowball sampling (snowball). The selected sample includes respected community figures who play an important role in the community and the people who help in the process of postpartum maternal health care in the Malayan community (traditional healers or parents who care for postpartum mothers with Malayan customs). The sample also includes the postpartum mothers who received care during the postpartum period.

Data analysis in this research uses Miles and Huberman's (2002) interactive model of

ISSN: 2709-0159 (Print)

Copyright (C) 2020, Journal of Scientific Research in Medical and Biological Sciences (JSRMBS), Under the license CC BY- 4.0 
data analysis techniques, namely Data Reduction, Data Presentation, and Conclusion Drawing / Verification. All the clinical procedures were carried out following the protocols approved by the Ethics and Review Committee Midwifery Study Program, Hasanuddin University, Indonesia.

\section{Results and Discussion}

\section{Postpartum Maternal Health Care for Malayans in Pontianak}

The mixing of Malayan and Buginese tribes results in inter-cultural appropriation. Hence, the findings related to postpartum health care in the Malayan community are rich and more diverse. This is considered useful and it is carried out by the local community. The habit also becomes a tradition that finally unconsciously becomes an obligation that must be done. One example of a Bugis custom that is unwittingly a compulsory ritual performed by the Malayan tribe in Pontianak is 'sacrifice'. It is carried out in important events in their life cycle (such as at birth, circumcision, marriage) and at other traditional activities. This is done to ask for salvation.

Health care during the postpartum period carried out by Malayan people becomes a series of interdependent procedures. It starts from the first day of to the fortieth day after giving birth. What the Malayan people do during postpartum health care is that they use different herbs and drink certain home-made stew. They resort to these traditional habits and use 'param' and 'pilis'. In addition, the mother's body is continually massaged for forty days. There are also restrictions and suggestions during the postpartum period in the Malayan community in Pontianak. These include abstinence and recommendations in terms of food consumed and activities that may and may not be carried out, and also clothing that should be worn during the postpartum period.

There are three types of stew and herbs that mothers must drink for forty days after giving birth. The three types of stew and herbal medicine are named fade, wind, and veins. In general, the ingredients used in stew and herbal medicine are turmeric, ginger, Zingiber cassumunar, black cumin, cloves, garlic, and coriander. Specific ingredients in the three stews and herbs cannot be explained because the participants refused to discuss about the whole of the mixture. There are special reasons related to the beliefs that they have been practicing for a long time, such as how this treatment can only be passed on to their family line. Some Malayans explain that this is the inspiration that they received from dreams and cannot be carelessly given to others.

The next treatment after drinking stew and herbal medicine during the postpartum period, the stomach will be 'Tapal' and the whole body will be given a powder called 'Param'. In addition, on the forehead above the eyebrow, they put 'Pilis'. The purpose is to use a poultice so that after giving birth, the stomach can enlarge as normal and not sagged. The poultice is also believed to restore the size of the uterus and help it return to normal. A poultice is a wood or coconut wood-burning ash which is given tamarind, placed on the stomach under the octopus.

After pairs of octopus in the stomach, then the mother's stomach will be curved

ISSN: 2709-0159 (Print)

Copyright (C) 2020, Journal of Scientific Research in Medical and Biological Sciences (JSRMBS), Under 
(sagged). According to their beliefs, the aim is to restore body shape to be back to normal, warm the stomach, help the healing process after childbirth, and keep the role of the kidneys from going down. 'Bengkung' (curving exercise) is used for three days after giving birth to the fortieth day of postpartum. Bengkung is not only used on the stomach but it is usually used also on the thighs. The aim is to limit the mother's movements so that the healing process goes fast. The third kind of herbs/stew that is used by Malay people is 'param'. The purpose of using 'param' is to maintain the body's warmth, blood circulation and to prevent swelling of the body and breast of the mother. It can also smooth the skin. Param is usually used for 40 days during postpartum period. Param is made from rice added with spices such as galangal, Liya (ginger), coriander, and then crushed and applied to the body.

Moreover, 'pilis' is also done during postpartum. The aim is to put 'pilis' so that the mother's eyes after giving birth do not get infected. It is also believed that it reduces redness, itching, swelling called meroyan, and menaes in Malay. According to their tradition, if it is left unchecked, it can cause blindness, due to the fact that there are broken veins in the eye area. Pilis basic ingredients are from Java chili or Sepang wood and other additional spices, depending on the herbalist who formulated. Pilis is used approximately for twenty days of postpartum.

Postpartum mothers who experience a prolapsed uterus will be carried out by the prone Ngangkil, pressing on the stomach to lift up the womb. The position of the shaman's hands is placed under the stomach above the genitals. Postpartum mother takes the lying position, legs bent (dorsal recumbent). The outside of the vagina is covered with cotton. With two hands and sitting position, the shaman will do the picking while putting his hands between his stomach and genitals, then massage to the top toward the chest. This is done while pressing the mother's vagina with the heel of the foot. The goal is that the prolapsed uterus rises back to its original position.

\section{Impacts if Postpartum Care is not taken according to the Malayan Customs}

The benefits of every health care carried out are to have a positive impact on the body, thus helping in the recovery of maternal health during the postpartum period. The long-term impact that has been felt by several participants is namely that the body does not get easily sick. The use of 'pilis' prevents premature blindness in old age. In addition, consuming herbal medicine routinely keeps the female organs healthy and prevents leucorrhoea. By consuming natural ingredients, the postpartum mother maintains the youthfulness of her body.

In addition to the benefits, there are also health effects if not doing postpartum health care in Malayan people in Pontianak. One of the most common health effects on Malayan people, if they do not perform health care during the postpartum period, is a Bentan. 'Bentan' is a complication that occurs during childbirth and it is believed to happen due to the dilatations of the recommended rituals and cultural traditions. If a postpartum mother suffers from 'bentan', the simple explanation according to the Malayan tradition is that the mother did not follow the recommendations that have been told. 


\section{Discussion}

From the interviews with the participants who have experienced bentan(shock), they explained that the pain of bentan is more painful than giving birth. All the participants who experienced bentan ascribe it either to violating the established taboos and or that they did not carry out the recommended procedures, such as performing heavy activities, tripping toes, not doing curve exercise, not using param, pilis, and others. The symptoms experienced during the bentan are almost the same, namely shivering, fever, swollen breasts. At the level of impact that is quite severe, the postpartum mother may bleed and the uterus drops into the vaginal canal. Refraining from putting a black thread on the big toe is also believed to be the cause of the bentan.

The impact, if not doing postpartum maternal health care according to the Malayan tradition, is not only the bentan. Women experience major changes in the postpartum period. In this period, the frequency of specific diseases increases with maternal morbidity and mortality (Kleppel et al., 2016; East et al., 2012). The puerperium or postpartum period is the recovery period of the reproductive organs after giving birth (Shaw et al., 2016). The results of this study indicate that there is a long-term impact that will be felt by the mother, namely the body gets easily tired and easily sick. The female organs may also endure leucorrhoea. In addition, it is revealed that consuming 'Ilisha Elongata' during the postpartum period causes severe diseases. Another possible disease is vaginal fistula.

\section{Conclusion and Suggestion}

This study aimed at measuring the effect of postpartum care on Malayan mothers in Indonesia. Health impacts on mothers during the postpartum period can be directly felt in the body by becoming fresher and healthier. In addition, taking postpartum care according to the Malayan traditions is believed to have effect on the mother's body by gradually improving and recovering. However, if postpartum care is not taken according to the Malayan tradition in Pontianak, the results are that the mother is subjected to Bentan. Other impacts that occur if not doing postpartum maternal health care based on the Malayan tradition are that the body gets easily tired. Moreover, it is believed that the postpartum mother can become easily sick if she does not receive care in the Malayan manner. More importantly, if the exercises and procedures suggested in the Malayan tradition are not practised well, the female organs are easily wet (leucorrhoea). Furthermore, it is revealed that consuming Ilisha Elongata during the postpartum period results in severe complications.

\section{Conflict of Interest}

The author declares no conflict of interest

\section{Funding:}

No Funds received for this study. 


\section{References}

Pitriani R, Andriyani R. (2014). Complete Guide to Normal Postpartum Maternity Care. (ASKEB III). Yogyakarta: Deepublish.

Mitra, M., Clements, K. M., Zhang, J., Iezzoni, L. I., Smeltzer, S. C., \& Long-Bellil, L. M. (2015). Maternal characteristics, pregnancy complications and adverse birth outcomes among women with disabilities. Medical care, 53(12), 1027.

Fisher, J., de Mello, M. C., \& Izutsu, T. (2009). Pregnancy, childbirth and the postpartum period. Mental Health Aspects of Women's Reproductive Health, 8.

Misri, S. (2010). Shouldn't I be Happy: Emotional Problems of Pregnant and Postpartum Women. Simon and Schuster.

Nour, N. M. (2014). Global women's health-A global perspective. Scandinavian Journal of Clinical and Laboratory Investigation, 74(sup244), 8-12.

Triana A, Damayanti I., Afni S., and Yanti J. (2015). Textbook of Maternal and Neonatal Emergencies. Yogyakarta: Deepublish.

Ministry of Health. Profil Kesehatan RI 2017. 2017; Jakarta: Kemenkes RI.

Health Office of West Kalimantan Province. Profil Kesehatan Provinsi Kalimantan Barat Tahun 2016. 2016;Provinsi Kalimantan Barat: Dinas Kesehatan.

Health Office of Pontianak City. Profil Kesehatan Kota Pontianak Tahun 2017. 2017;Pontianak: Dinas Kesehatan

Say, L., Chou, D., Gemmill, A., Tunçalp, Ö., Moller, A. B., Daniels, J., ... \& Alkema, L. (2014). Global causes of maternal death: a WHO systematic analysis. The Lancet Global Health, 2(6), e323-e333.

Vogel, J. P., Souza, J. P., Mori, R., Morisaki, N., Lumbiganon, P., Laopaiboon, M., ... \& Mittal, S. (2014). Maternal complications and perinatal mortality: findings of the World Health Organization Multicountry Survey on Maternal and Newborn Health. BJOG: An International Journal of Obstetrics \& Gynaecology, 121, 76-88.

Huberman, M., \& Miles, M. B. (2002). The qualitative researcher's companion. California : Sage Publications.

Shaw D, Guise JM, Shah N, Gemzell- Danielsson K, Joseph KS, Levy B, and Main EK. (2016). Drivers of maternity care in high-income countries: can health systems support woman-centred care?. The Lancet. 2016;388(10057):2282-2295.

Kleppel, L., Suplee, P. D., Stuebe, A. M., \& Bingham, D. (2016). National initiatives to improve systems for postpartum care. Maternal and child health journal, 20(1), 6670.

East, C. E., Sherburn, M., Nagle, C., Said, J., \& Forster, D. (2012). Perineal pain following childbirth: prevalence, effects on postnatal recovery and analgesia usage. Midwifery, 28(1), 93-97. 